\title{
Hannah Arendt e o espaço público como possibilidade de se pensar a emancipação política das mulheres a partir da figura de Rosa Luxemburgo
}

\author{
Hannah Arendt and the public space as a possibility \\ to think about the political emancipation of women \\ from the figure of Rosa Luxemburg
}

Jessica Thainá Ribeiro Viana ${ }^{1}$

1 Graduanda em Licenciatura Plena em Filosofia pela Universidade Federal do Pará, Brasil.

E-mail: thainavianna26@gmail.com Orcid: http://orcid.org/0000-0002-6917-5357 Lattes: http://lattes.cnpq.br/2138998262807955

RESUMO: Este trabalho tem por objetivo analisar a figura de Rosa Luxemburgo (1871-1919) como exemplo de ascensão das mulheres ao espaço público tal qual descrito por Hannah Arendt (1906-1975), e refletir sobre os motivos que permitiram o negligenciamento histórico de Luxemburgo apesar de sua ascensão ao espaço público. Tendo em vista que apesar de ter tido grandes contribuições teóricas e práticas e ter ascendido ao espaço público, ainda assim Rosa Luxemburgo fora negligenciada, estereotipada por meio da figura ora sanguinária, ora romantizada, e por esses motivos Arendt acredita que a política alemã não obteve o reconhecimento devido que mereceria nem em vida e nem em morte. Para tanto, utilizaremos a distinção entre espaço público e espaço privado de Arendt, presente na obra $A$ condição bumana (1958), bem como seu ensaio intitulado "Rosa Luxemburgo: 1871-1919", presente na obra Homens em tempos sombrios (1968) e a obra Rosa Luxemburgo on o Preço da Liberdade (2008) de Jörn Schütrumpf. Por fim, corroboramos com Hannah Arendt e trazemos também Jörn Schütrumpf para reafirmar que apesar de ter ocorrido uma pequena mudança em sua reputação, e algumas pessoas até saberem o nome de Rosa Luxemburgo, diante de sua grande contribuição teórica e prática, seu reconhecimento acadêmico e político ainda é insuficiente, e acreditamos ainda ser possível um reconhecimento ainda que tardio da importância da figura de Rosa Luxemburgo para o pensamento teórico/filosófico político contemporâneo.

Palavras-chave: Hannah Arendt; Rosa Luxemburgo; negligenciamento histórico.

ABSTRACT: This paper is aimed to analyse the figure of Rosa Luxembourg (1871-1975) as an example of the ascension of women to public space as described by Hannah Arendt (1906-1975), and to reflect on the reasons that allowed her historical oblivion. Given that despite having made major theoretical and practical contributions and ascending to the public space, it was still neglected, stereotyped between the now bloodthirsty, sometimes romanticized figure, and for these reasons Arendt believes that Luxembourg was not recognized she deserved neither in life nor in death. For this, we will use what Arendt wrote about Luxembourg, based on the essay entitled "Rosa Luxemburg: 1871-1919", present in the work Men in Dark Times (1968), as well as his distinction between public and private space present in the work The Human Condition (1958) and Rosa Luxemburg, or: The Price of Freedom (2008) by Jörn Schütrumpf. Finally, we support Hannah Arendt and also bring Jörn Schütrumpf to reaffirm that, although there has been a slight change in her reputation, and some people even know Rosa Luxemburg's name, in face of her great theoretical and practical contribution to her academic and political acknowledgement. It is still insufficient, and we still believe that a late recognition of the importance of the figure of Rosa Luxemburg for political theoretical / 
philosophical thought is still possible.

Keywords: Hannah Arendt; Rosa Luxemburg; historical oblivion

\section{Introdução}

Este trabalho destaca que, apesar de ter sido negligenciada pela história, Rosa Luxemburgo é de grande importância para a compreensão do pensamento político Ocidental. Assim, buscaremos refletir sobre sua ascensão de forma majestosa ao espaço público tal qual descrito por Arendt, como possibilidade para se pensar a permanência das mulheres dentro desse espaço. Para tanto, partiremos da leitura de Hannah Arendt a respeito da vida e da obra de Luxemburgo e de seu diagnóstico acerca de seu negligenciamento histórico. Utilizaremos também Jörn Schütrumpf, comentador de Rosa Luxemburgo, para reforçar a importância de sua vida e de sua obra diante de seu insuficiente reconhecimento. Buscaremos na distinção entre o espaço público e o espaço privado presente na obra A Condição Humana de Hannah Arendt, refletir sobre a ascensão de Rosa Luxemburgo ao espaço público, bem como os motivos pelos quais sua permanência nele foi negada. Como aponta Arcary “a reabilitação teórica e política de Rosa está ainda por ser feita diante dos olhos da nova geração” (ARCARY, 20019), sendo assim, o nosso objetivo é refletir sobre o porquê, apesar de ter ascendido ao espaço público utilizando os dispositivos expostos por Arendt, ainda assim o negligenciamento histórico de Luxemburgo se faz presente, mesmo após 100 anos de sua morte.

Segundo Martins "o espaço público, bem como as formas de a ele ter acesso e participar, têm sido modulados a partir de um entendimento predominantemente masculino" (2005, p. 701), e por este motivo ainda hoje as mulheres são usurpadas do domínio público mesmo depois de já estarem inseridas nele, assim como ocorreu com Luxemburgo. Com Arendt temos a possibilidade de pensar formas de se ter acesso ao espaço público partindo da reflexão de uma mulher que rompe com o cânone masculino, enquanto que na figura de Luxemburgo vemos esse exemplo de participação através da ação no espaço público teorizado por Arendt. Ao analisar a leitura de Arendt sobre a vida e a obra de Rosa Luxemburgo pretendemos refletir sobre quais seriam as contribuições de ambas para que possamos pensar uma emancipação política das mulheres. Pretendemos refletir sobre o que podemos obter e de que forma o pensamento dessas autoras pode ser utilizado para pensarmos sobre a emancipação das mulheres no espaço público, e consequentemente na política contemporânea.

\section{Hannah Arendt e a distinção entre o espaço público e o espaço privado}

Hannah Arendt, em sua obra Entre o Passado e o Futuro (1961), ressalta a importância de se fazer distinções entre conceitos, a fim de evitar um consenso gerado com a modernidade que permite que "cada um de nós tem o direito de definir seus termos" (ARENDT, 2016, p. 132), o que acaba por nos fazer perder a vivência em um mundo comum, onde se passa a viver em um mundo desprovido de significado. Desta forma, se faz necessário realizar uma análise de uma das principais distinções presente no pensamento político da filósofa, que trata da diferenciação entre o espaço público e o espaço privado, a fim de compreender como se dá a ascensão ao espaço público através da ação política.

O espaço público e o espaço privado, no entender de Arendt (2018), existem como esferas separadas e distintas desde a criação da cidade-estado grega. Porém, um fenômeno novo que surge com a modernidade presente no estado-nação, dificulta a decisiva divisão entre os domínios públicos e privado. Tal fenômeno seria a eclosão da esfera social. Uma das primeiras distinções para se compreender a diferença entre tais 
domínios, se dá já no início do segundo capítulo da obra $A$ Condição Humana, no qual o político é distinguido do social.

Arendt inicia fazendo um apanhado histórico de termos e distinções, que se estende da Grécia antiga à modernidade. $\mathrm{Na}$ busca de resgatar as origens que diferenciavam o espaço público do privado e âmbito político do social. No primeiro capítulo da obra supracitada, Arendt nos apresenta três atividades que segundo ela são fundamentais para se compreender a condição humana, a saber: o trabalho, a obra e a ação.

O trabalho é a atividade isolada realizada por necessidade de sobrevivência, ou seja, está ligado aos aspectos biológicos com os quais o homem relaciona-se com a natureza usando a subsistência individual, ligada ao ciclo vital do homem. Desta maneira, "a condição humana do trabalho seria a própria vida" (ARENDT, 2018, p. 9).

Por sua vez, a obra é a atividade "correspondente à não-naturalidade da existência humana" (ARENDT, 2018, p. 9), é responsável pela fabricação do mundo artificial e dos objetos fabricados para o uso. Existe uma diferença entre os objetos produzidos pelo animal laborans e o homo faber, enquanto o animal laborans produz objetos para o consumo o homo faber produz objetos para o uso. A fabricação tem um começo e um fim definido, diferente do trabalho que segue um movimento cíclico. A condição humana desta atividade é a mundanidade.

Finalmente, a ação, que é "a atividade política por excelência” (ARENDT, 2018, p. 11), e a única atividade que ocorre diretamente entre os seres humanos, tendo como condição humana a pluralidade, conceito chave para entendermos a ação política arendtiana. Ligada à nossa capacidade de agir em conjunto, a ação para Arendt, é responsável pela preservação de nossos corpos políticos, bem como pela criação de condições fundamentais para a lembrança, ou seja, para a história. Nas palavras de Arendt (2018, p. 28) a “ação é prerrogativa exclusiva do homem; nem um animal nem deus é capaz de ação, e só a ação depende inteiramente da constante presença de outros".

Com isso, na tentativa de distinguir o espaço público do espaço privado surge antes a necessidade de distinguir o político do social. Por conta dessa relação de dependência entre a ação e a presença de outros surgem alguns equívocos que culminam na perda de distinção entre o social e o político. Sobre isso Arendt comenta:

Essa relação especial entre a ação e estar junto parece justificar plenamente a antiga tradução do zõon politikõn de Aristóteles como animal socialis, que já encontramos em Sêneca e depois, com Tomás de Aquino, tornou-se a tradução consagrada: homo est naturaliter politicus, id est, socialis ("o homem é, por natureza, político, isto é, social"). Melhor que qualquer teoria elaborada, essa substituição inconsciente do político pelo social revela até que ponto havia sido perdida a original compreensão grega da política. (ARENDT, 2018, p. 28)

Por isto, a autora identifica essa relação entre a "ação" e o "estar junto" presente na história da filosofia, que consequentemente acarreta na perda de diferenciação entre aquilo que é político e o que é social. Buscando com isso ressaltar que, para haver a possibilidade de distinguir o público do privado, antes precisamos compreender a diferença significativa entre considerar o homem um animal social ou um animal político. De acordo com Arendt (2018) o uso latino da palavra social tinha um significado diretamente político, porém para os gregos a companhia social era uma necessidade da vida biológica que não nos diferenciava de outros animais. Diante disso, o fato de o homem não poder viver isolado, fora da companhia de outros homens não é uma característica especificamente humana.

Arendt segue em um caminho historiográfico para mostrar que, embora ocorram algumas confusões 
de tradução que podem dificultar a distinção entre a esfera pública e a esfera privada, a separação entre elas acontece desde o surgimento da cidade-Estado. Entretanto, na concepção moderna de sociedade com o surgimento do Estado-nação tal distinção tornou-se cada vez mais difícil, principalmente por conta do advento da esfera social que não é nem privada nem pública. O interesse de Arendt passa a ser justamente a dificuldade de distinção entre a esfera da pólis e a esfera do lar nas quais se baseava o antigo pensamento político. Partindo desse caminho historiográfico de distinções, a filósofa, apresenta uma definição própria de espaço público e espaço privado.

Existem dois fenômenos que Arendt relaciona com o termo público, mas que vale ressaltar, não são iguais. O primeiro lugar diz respeito a "aparência - aquilo que é visto e ouvido pelos outros e por nós mesmos - [que] constitui a realidade” (ARENDT, 2018, p. 61). Esta é uma das principais características do espaço público. Há ainda o fato de que as experiências individuais também poderem ser levadas a público, desde que sejam "transformadas, desprivatizadas e desindividualizadas, por assim dizer, de modo que assumam um aspecto adequado à aparição pública” (2018, p. 61). Em um segundo significado, o termo público concerne à própria realidade, mas não somente à realidade concreta do mundo, como também ao mundo de coisas criadas pelo próprio ser humano, através do trabalho e da obra. Nas palavras de Arendt:

O termo 'público' significa o próprio mundo, na medida em que é comum a todos nós e diferente do lugar que privadamente possuímos nele. Esse mundo, contudo, não é idêntico à Terra ou à natureza, enquanto espaço limitado para o movimento dos homens e condição geral da vida orgânica. Antes, tem a ver com o artefato humano, com o que é fabricado pelas mãos humanas, assim com os negócios realizados entre os que habitam o mundo feito pelo homem. (ARENDT, 2018, p.65)

Dito isto, o espaço público seria esse mundo comum entre os seres que os habitam, esse espaçoentre os humanos, que nos permite viver na companhia uns dos outros, um espaço de relações. Se caracterizando pela aparência, pela visibilidade, pelas quais se fala e se é ouvido, pelas quais se é inserido através de palavras e atos. Por isso também, o espaço da ação, da pluralidade, onde existe sempre a possibilidade de se iniciar algo novo, e por estes motivos é também a esfera da liberdade. Se relaciona também com a possibilidade de uma tradição a ser estabelecida ou a ser recriada, tendo em vista que se refere ao passado e ao futuro, por ter um caráter transcendente da vida humana. Com isso, a esfera pública permite esse caráter também de preservação das obras, dos grandes feitos humanos, possibilitando a imortalidade da obra diante da vida de seres mortais. E por estes motivos, ele, o espaço público, é político por excelência.

Ao contrário do termo público que tem uma dicotomia em seu sentido, o termo privado vem da ideia original de privativo (ARENDT, 2018, p.72). O espaço privado tolhe o humano da realidade que é constituída pelo fato de ser visto e de ser ouvido por outros seres humanos. Partindo desta perspectiva que "a privação da privacidade reside na ausência de outros, para estes, o homem privado não aparece, e, portanto, é como se não existisse" (ARENDT, 2018, p. 52). Consequentemente, anula a relação que existe no mundo comum e consequentemente subtrai a possibilidade do ser humano de realizar feitos permanentes no mundo. De acordo com Arendt:

Viver uma vida inteiramente privada significa, acima de tudo, estar privado de coisas essenciais a uma vida verdadeiramente humana: estar privado da realidade que advém do fato de ser visto e ouvido por outros, privado de uma relação 'objetiva' com eles decorrente do fato de ligar-se e separar-se deles mediante um mundo comum de coisas, e privado da possibilidade de realizar algo mais permanente que a própria vida. (ARENDT, 2018, p. 52) 
Desta maneira, o ser humano é privado da própria realidade, que só é possível ser vivida na presença de outros. Quando privado dessa relação entre pares, se perde também a possibilidade de se imortalizar através de grandes feitos, que quando realizados se tornam mais permanentes que a vida humana. Ou seja, o espaço privado diz respeito a manutenção da vida, está ligado as necessidades e as atividades de sobrevivência, além de ter como característica a desigualdade, tendo em vista que se trata do espaço do lar (oikia), onde o déspota é soberano e atua com um poder coercitivo. O domínio privado se limita somente aos interesses pessoais, dos quais o ser humano é condicionado a manutenção da sobrevivência biológica e dos cuidados com o lar e a família, por esses motivos, o espaço privado se configura como um espaço prépolítico.

Desta maneira, podemos observar que é através da ação, que o indivíduo se insere no espaço público. E que o espaço privado, que historicamente foi delegado as mulheres, priva o indivíduo da liberdade e da pluralidade. Enquanto que o espaço público, mais suscetível aos homens, seria o espaço político por excelência e o espaço da pluralidade e da ação. Diante dessa rígida distinção posta entre o espaço público e o espaço privado e compreendendo a ação como uma característica necessária para ascender ao espaço público, o que pretendemos é mostrar como a figura de Rosa Luxemburgo se utilizou da ação política, tal como descreve Arendt, para buscar tal ascensão.

\section{Hannah Arendt leitora de Rosa Luxemburgo}

A interpretação de Hannah Arendt sobre a vida e a obra de Rosa Luxemburgo, presente em seu ensaio intitulado "Rosa Luxemburgo (1871-1919)" que se encontra na obra Homens em Tempos Sombrios é muito particular. Tal interpretação da autora nos leva a crer que Rosa Luxemburgo não teve o reconhecimento devido que mereceria em vida nem em morte. Tendo em vista que para Arendt, o pensamento e a importância prática política de Luxemburgo foram negligenciados pela história.

Em seu ensaio, Arendt ressalta a importância historiográfica das biografias inglesas que buscam apresentar a história por meio de uma grande figura de sua época. Assim, as biografias eram escritas a respeito de grandes estadistas ou pessoas que empenhavam uma certa relevância para a história. Desta maneira, a autora segue de forma mais direcionada comentando a respeito da biografia de Rosa Luxemburgo escrita por John Peter Nettl e publicada em dois volumes, em 1996.

Ao partir do entendimento de que as biografias possuem tal relevância e são direcionadas a grandes nomes históricos, Arendt (2008) observa que fazer uma biografia sobre Rosa Luxemburgo seria um tanto quanto improvável. Tendo em vista que Luxemburgo era uma figura marginalizada que teve breves momentos de esplendor, sejam por meio da ação ou da escrita. A filósofa indaga-se sobre qual seria o feito de Nettl com tal biografia. Segundo Arendt "foi precisamente o êxito - êxito mesmo em seu próprio mundo de revolucionários - que foi negado a Rosa Luxemburgo em vida, na morte e após a morte” (2008, p. 42), e resgatar esse êxito foi a façanha de J. P. Nettl. Dito isto, a autora segue seu ensaio que tem como "pano de fundo" justamente esse negligenciamento histórico do qual segundo ela Rosa Luxemburgo foi vítima.

Um dos apontamentos importantes notados por Arendt se trata da criação de um mito em cima da figura de Rosa Luxemburgo após sua morte, que pairava entre duas vertentes, uma romantizada e outra sanguinária, ambas regadas por um excesso desmedido. Ora lembrada como a sanguinária "Rosa Vermelha", ora lembrada de forma romantizada como a poetisa que escrevera a respeito de pássaros e flores de dentro da prisão. Além de ter sua reputação atrelada a clichês como os de "mulher briguenta', uma 'romântica' que não era nem 'realista' nem científica” (ARENDT, p. 46), condenando assim suas obras ao campo da 
indiferença. Vale ressaltar, que ainda hoje, a figura da mulher que se faz visível seja ocupando o espaço público ou defendendo suas ideias ainda é tachada nessa linha tênue que existe no estereótipo do feminino, entre a romântica ou a histérica.

Apesar de Arendt não direcionar sua crítica especificamente ao gênero de Luxemburgo, vemos neste trabalho este marcador, o gênero, como uma característica relevante para compreendermos o seu negligenciamento histórico. Vale ressaltar, entretanto, que Nettl não considerou os mitos criados a respeito de Luxemburgo, nas palavras do biógrafo, sua tarefa era de "reconstruir a história de uma pessoa, de um movimento e de uma época” (1974, p. 9. Tradução nossa), segundo Arendt era a de recuperar Luxemburgo para a vida histórica.

A autora ressalta que o pensamento de Rosa Luxemburgo ainda era presente no surgimento dos novos movimentos de esquerda da época. Porém, com o passar do tempo e com o amadurecimento de seus líderes, tais movimentos acabaram por retornar a velha esquerda. Com isso, acabavam se afastando e esquecendo o antigo entusiasmo por Luxemburgo bem como seus sonhos de juventude. Este afastamento era feito de maneira drástica sem ao menos buscarem realizar uma leitura de suas obras na tentativa de compreendê-las, acabavam por achar mais simples descartar suas ideias.

Desse modo, apesar de ter surgido uma corrente teórica com o objetivo de trabalhar com o pensamento de Rosa Luxemburgo, conhecida como "luxemburguismo" tal movimento não chegou nem a ser levado a sério e foi tratado dentro do partido como "uma doença infantil inofensiva" (ARENDT, p. 46), deixando o pensamento de Rosa Luxemburgo fadado ao esquecimento, ou, apenas lembrado como um pensamento equivocado. Arendt, com um certo pesar, chega a afirmar que sobre o que Luxemburgo "escreveu ou falou nada sobreviveu, exceto sua crítica surpreendentemente acurada à política bolchevique durante os estágios iniciais da Revolução Russa" (ARENDT, 2008, p. 46).

O trabalho biográfico de Nettl é de grande importância para Arendt, por ser "o primeiro retrato plausível dessa mulher extraordinária” (ARENDT, 2008, p. 52), que teria sido Rosa Luxemburgo. No entanto, o biógrafo comete um erro ao enfatizar o que seria, segundo ele, característico de Luxemburgo, a saber, "sua ambição e senso carreirista", sendo que ela nutria um certo desprezo por figuras do partido alemão que buscavam tais objetivos. O que para Nettl soa como ambição, para Arendt não seria mais do que uma força natural que a levou bruscamente para os assuntos públicos.

Arendt aponta também o fato de J. P. Nettl não ter levado em consideração um aspecto de grande relevância em nossa hipótese para compreendermos o apagamento histórico do qual Luxemburgo foi vítima, que diz respeito as implicações que decorrem de ser uma mulher dentro do espaço público. Nas palavras da autora:

Há um outro aspecto de sua personalidade que Nettl destaca, mas cujas implicações parece não compreender: que ela era tão 'autoconscientemente uma mulher'. Isso em si colocou certas limitações ao que, de outra forma, poderiam ter sido suas ambições - pois Nettl não lhe atribui mais do que seria natural para um homem com seus talentos e oportunidades. (ARENDT, 2008, p. 53).

Entretanto, destacamos que tais limitações não diziam respeito ao gênero feminino enquanto condição, mas sim a uma questão estrutural da sociedade na qual Rosa Luxemburgo estava inserida. A mulher estava delegada muito mais ao espaço privado, no cuidado do lar, com pouca ou nenhuma possibilidade de ascensão ao espaço público. Tanto que a própria Luxemburgo, após uma autoavaliação, chegou a afirmar "meio a sério, meio a brincadeira [que] nascera 'para cuidar dos gansos', [...] se as circunstâncias do mundo não tivessem ferido seu senso de justiça e liberdade” (ARENDT, 2008, p. 47). Arendt ressalta que 
Luxemburgo era "autoconscientemente uma mulher", por este motivo a autora chega a afirmar que Luxemburgo seria "uma forasteira, não só por ser e permanecer uma judia polonesa num país que lhe desagradava e um partido que logo viria a desprezar, mas também por ser mulher" (ARENDT,2008, p. 53).

Um ponto a ser ressaltado na leitura de Arendt, é a forma como a autora coloca Luxemburgo como uma figura decisiva para o curso da história moderna alemã e para o movimento de esquerda da época. Segundo Arendt (2008, p. 44) a morte de Rosa Luxemburgo teria sido "um divisor de águas entre duas eras na Alemanha". E o movimento de esquerda diante de tal acontecimento entraria em um processo de divisão sem retorno.

O afastamento de Rosa Luxemburgo do Marxismo é uma leitura muito particular que Arendt faz, e duramente criticada pelos estudiosos de Luxemburgo. A autora caracteriza Luxemburgo como uma marxista não ortodoxa, porém chegando ao ponto de se questionar se realmente seria marxista. De acordo com Storløkken "a dúvida de Arendt a respeito do marxismo de Luxemburg é em grande medida influenciada por sua própria interpretação do marxismo" (STORLØKKEN, 2004, p. 6). Arendt chega a reconhecer em Marx o mérito de tentar romper com a tradição política, porém, o acusa de não ter sido radical o suficiente, por ainda estar preso ao método dialético do pensamento político tradicional.

Ao contrário dos que costumavam chamar o pensamento de Rosa Luxemburgo de infundado e equivocado, Arendt busca mostrar que tanto a teoria quanto o senso aguçado de realidade da pensadora a fizeram alçar grandes voos e entrar para a história como uma grande figura dentro do pensamento político. Arendt cita um ocorrido em fevereiro de 1914, quando Luxemburgo fora indiciada por “'incitar' as massas à desobediência civil em caso de guerra" (ARENDT, p. 45), e comenta com um teor sarcástico, que para uma mulher que "sempre estava errada" seria irônico ser julgada por tais acusações, principalmente poucos meses antes do início da Primeira Guerra Mundial.

Diante de tudo isso, Arendt aponta como importantes contribuições de Luxemburgo a sua leitura não ortodoxa de Marx, na sua obra $A$ acumulação do capital, comparando inclusive com a grandiosidade dos escritos de Marx. Além de seu "agudo senso de realidade e rigorosa evitação de clichês" (ARENDT, 2008, p. 51), seu posicionamento contrário a guerra, a deterioração moral dos partidos, entres outras ideias de grande relevância e importância para se pensar a respeito da história do pensamento político. Diante de tais contribuições, Arendt aponta que:

É de se querer acreditar que ainda há esperanças de um reconhecimento tardio de quem foi e do que fez Rosa Luxemburgo, e de se esperar que finalmente encontre seu lugar na educação dos cientistas políticos nos países do Ocidente. Pois o sr. Nettl tem razão: 'Suas ideias pertencem a todos os lugares em que se ensine seriamente a história das ideias políticas.” (ARENDT, 2008, p. 66)

Isto posto, Arendt acreditava que ainda fosse possível trazer a tona o reconhecimento do qual Luxemburgo merecia diante de tamanha importância de seu pensamento e de suas ações, a fim de que se pudesse ter uma melhor compreensão do pensamento político de sua época. Para finalizar, supomos que o objetivo de Arendt ao escrever sobre Rosa Luxemburgo era também o de fazer parte desse resgate histórico, junto com J. P Nettl, de uma figura tão importante para o pensamento político. Tendo em vista que Luxemburgo foi uma agente histórica que realizou grandes feitos, e partindo do pressuposto de que contar a história de uma pessoa é torna-la visível, logo, resgatá-la para a vida histórica. 


\section{Rosa Luxemburgo e sua ascenção ao espaço público}

E por que Arendt apreciava tanto a figura de Luxemburgo? Por que Luxemburgo fora esquecida pela história do pensamento político? E porque sua ascensão ao espaço público causou tanto desconforto nos homens de sua época? Essas são questões que perpassam o objetivo deste artigo. Na busca de sanar tais questionamentos, nos juntamos a Nettl e Arendt na tarefa de fazer um resgate histórico de Rosa Luxemburgo para a história e compreensão teórico/filosófico do pensamento político ocidental. Demonstrando como a vida e a obra de Rosa Luxemburgo são provas de sua ascensão ao espaço público tal como o descrito por Arendt, porém, por ser mulher, seu êxito e permanência dentro desse espaço o foi negado.

De acordo com Schütrumpf, Rosa Luxemburgo sempre se manteve fiel "à unidade entre palavra e ação" (2015, p. 22), e estes eram os pressuposto necessários para se inserir no espaço público de acordo com Arendt. Para a autora é através de palavras e atos que acontece o nascimento ${ }^{1}$ político dos seres humanos, quando nos inserimos politicamente no mundo. Luxemburgo fora uma mulher de discurso, e por ter se inserido no espaço público, sempre soube defender suas ideias e se fez visível. Por conta disso, Schütrumpf (2015) aponta que seus adversários na maioria das vezes atacavam sua aparência física para tentar diminuíla politicamente, ao invés de atacarem suas ideias. Assim como Arendt, ao analisar a biografia de Luxemburgo coloca a autora ao lado de grandes figuras masculinas de sua época, Schütrumpf coloca ao lado de dois grandes nomes, a saber, Antonio Gramsci e Che Guevara. Ambos com grande reconhecimento e notoriedade, enquanto que "Rosa Luxemburgo, no entanto, a mais complexa dos três, a maioria conhece apenas o nome e o destino, mas não o pensamento e a obra, e, na maioria das vezes, só como caricatura" (2015, p. 22. Grifo nosso).

Assim, seguimos na tentativa de compreender como, apesar de seus grandes feitos teóricos e práticos, Luxemburgo continua às margens da história do pensamento político, logo, a margem da filosofia. Em nossa hipótese, grande parte dessa marginalização advém do fato de se tratar de uma mulher que se negou a permanecer somente no espaço privado e ousou ascender ao espaço público. Pois como podemos perceber, Luxemburgo esteve ao lado de grandes intelectuais e ativistas de sua época, todos devidamente reconhecidos por suas palavras e seus atos, enquanto que ela segue sendo negligenciada nesse percurso histórico e filosófico do pensamento político. O que buscamos é mostrar como a pensadora, apesar ter seguido a "cartilha arendtiana" para alcançar o espaço público, mesmo assim foi marginalizada, apesar de ter se feito visível, foi pouco ouvida por seus arredores e até hoje pouco valorizada.

Rosa Luxemburgo, entre 1871 e 1919, desde muito jovem, se inseriu no movimento político de sua época. Ainda enquanto secundarista, aos 15 anos de idade, entrou para o movimento socialista na Polônia, que era clandestino na época. Aos 19 anos fora obrigada a deixar a Polônia por conta de perseguição política, partindo para Zurique, na Suíça, onde entrou na Universidade de Ciências Aplicadas. Fundou o Partido Social Democrata da Polônia (SDKP) em 1894, e em 1897 recebeu o título de Doutora, indo assim no ano seguinte morar na Alemanha. Já na Alemanha, em 1898 entrou para o Partido Social Democrata Alemão (SPD), onde teve conflitos ao perceber em alguns companheiros do partido um caráter reformista ${ }^{2}$ do

\footnotetext{
1 É importante ressaltar quando falamos em nascimento em Arendt que a autora distingue os conceitos de natalidade e de nascimento. A natalidade segundo a pensadora seria o fenômeno no qual novos seres nascem para mundo, enquanto que o nascimento se daria por meio das palavras e dos atos, no momento em que o ser humano se insere no mundo.

20 reformismo se tratava de uma corrente de intelectuais da esquerda que propuseram um revisionismo das bases teóricas do movimento., iniciado por Eduard Bernstein. Caracterizavam como utópicos os fundamentos teóricos da social democracia, apontando a necessidade de afastamento do que chamavam de ilusões revolucionárias,
} 
sistema capitalista, o que ela era radicalmente contra, pois defendia uma política revolucionária. Chegou a ser uma das dirigentes do partido, porém, passou a criar inimizades por conta dessa ala reformista presente no partido.

Em 1914 Luxemburgo apresentou uma proposta revolucionária contra a I Guerra Mundial, o que resultou em uma divisão dentro do partido e por este motivo fora indiciada e acusada de incitação à desobediência civil, como bem ressalta Hannah Arendt. Mas apesar de seu discurso inflamada fora derrotada e o partido aderiu a guerra. Em 1915 cria o grupo Spartakus juntamente com aliados em forma de protesto conta a adesão do Partido Social Democrata Alemão a Primeira Guerra, onde realizaram um trabalho de propaganda contra a guerra, e por este motivo foram perseguidos, o que culminou na prisão de Luxemburgo e seu companheiro Karl Liebknecht (1871-1919). Com Liebknecht, Luxemburgo juntamente com o grupo Spartakus organizou e fundou o Partido Comunista Alemão. No ano seguinte, 1919, Rosa Luxemburgo e Karl Liebknecht foram assassinados por paramilitares em Berlin, na Alemanha. Diante de tudo isso, Jörn Schütrumpf levanta um questionamento:

O que permanecerá dessa Rosa Luxemburgo, nascida em Zamość, Polônia, jogada nas águas do Tiergarten, em Berlin, de quem muitos conhecem certamente o nome e a história da morte, mas quanto ao resto, na maior parte das vezes, quase somente lendas? (SCHÜTRUMPF, 2015, p. 69)

Rosa Luxemburgo deixou um legado político e de resistência muito forte para aqueles que realmente buscam agir dentro do espaço público, buscando defender o seu caráter plural, e a manutenção da liberdade daqueles que compartilham desse mundo comum. Além de ter deixado uma contribuição teórica rica para pensarmos como se dava o pensamento político de sua época, obras como: A Acumulação do Capital (1913), Reforma Social ou Revolução (1899), A Revolução Russa (1922), entre outras. Luxemburgo refletiu sobre questões teóricas e práticas importantes para a compreensão de conceitos políticos como o de massas, de espaço público, de ação política, de liberdade. Como aponta Loureiro, Frigga Haug chega a "lembrar que Rosa foi elogiada por marxistas como Lênin, Mehring, Lukács como a melhor continuadora da obra de Marx em termos metodológicos" (LOUREIRO, 2010, p. 4)

No plano político e no privado, na teoria e na prática, Rosa Luxemburgo alcançou um nível que desde então só raras vezes foi atingido, quando foi denunciada e difamada, ela somente é tolerável - e útil para muitos, mesmo em nossos dias, como ícone mudo. (SCHÜTRUMPF, 2015, p. 70)

Luxemburgo teve grandes contribuições teóricas, concomitante com suas contribuições práticas para analisarmos o pensamento político. O espaço público, o qual ela alcançou a duras penas, mas no qual teve sua permanência negada, era de grande importância para o seu pensamento, assim como para o pensamento de Arendt, e era a condição primeira para qualquer democracia. Para além de ter buscado seus pares, de se fazer visível, de se inserir com palavras e atos no espaço público, bem como descreveu Arendt, Luxemburgo enfrentou duras resistências a suas ideias e ações. E apesar de ter realizado grandes feitos, sejam estes grandes discursos ou grandes obras, ainda sim teve sua imortalidade, tal como Arendt aponta ser possível dentro do espaço público, negada.

pregando assim uma política evolucionista e reformista do sistema capitalista. Enquanto que Luxemburgo defendia uma política revolucionária. Dessas discussões culminou a publicação do texto Reforma Social ou Revolução de Rosa Luxemburgo. (2015, p. 34) 


\section{Considerações finais}

Historicamente o espaço público tem sido negado à corpos femininos, não só em termos práticos, como em termos epistemológicos também. É evidente o silenciamento de gênero na tradição filosófica universalista moderna, onde as bases epistemológicas para se pensar a política, e consequentemente para se pensar o espaço público parte da definição de experiências de um grupo específico, a saber, masculino. Assim, o homem inicia sua busca teórica filosófica ditas "universais", porém, partindo do silenciamento das mulheres, e do apagamento da ideia de gênero. Surgindo assim um ideal universalista masculino.

Diante disso, utilizamos como ponto de partida a conceitualização do espaço público de um ponto de vista de uma mulher, presente na obra de Hannah Arendt. E a partir dessa teorização feminina do espaço público enquanto um espaço de pluralidade e de liberdade, fizemos uma tentativa de reflexão a respeito do papel prático feminino dentro do espaço público, para tanto, utilizamos a figura de Rosa Luxemburgo.

O nosso intuito no presente artigo foi mostrar como apesar de ascender ao espaço público, apesar das grandes contribuições teóricas e práticas, ainda sim, para Luxemburgo, a permanência neste espaço e a visibilidade devida, lhe foi negada. Rosa Luxemburgo em nada deixou a desejar, se comparada a todos os grandes homens de sua época que com ela dividiram o espaço público. Como bem aponta Schütrumpf, podemos até arriscar dizer que ela teria sido uma das mais brilhantes entre eles. Luxemburgo fora uma das maiores dirigentes revolucionárias, com um arcabouço teórico bem elaborado, com ideias bem definidas e com um senso de realidade aguçado, como foi apontado por Arendt. Luxemburgo conseguiu unir de fato teoria à prática. Conseguia fazer seu processo de abstração, mas sem deixar de se voltar para realidade. Seguia aquilo que Arendt tentou esclarecer em $A$ Condição Humana, quando diz que não pretende hierarquizar a vida ativa e a vida contemplativa. Afinal, as duas são de grande importância quando não são sobrepostas umas às outras.

Por fim, nosso objetivo foi para além de fazer um resgate da figura de Rosa Luxemburgo, e sim, repensar as formas como as mulheres são recebidas quando conseguem deixar o domínio privado, do cuidado do lar, para ascender ao domínio público, enquanto esse espaço de ação política e pluralidade tal qual descrito por Arendt. Utilizamos Rosa Luxemburgo como exemplo, mas existem milhares de outras mulheres na história da filosofia e na história da civilização de forma geral, que assim como Luxemburgo lutaram por aquilo que acreditavam, ocuparam o espaço público na busca de justiça e liberdade, mas foram silenciadas, as vezes pagando com a própria vida como Rosa Luxemburgo por ousarem deixar o domínio privado.

\section{Referências}

ARENDT, Hannah. (1958). A Condição Humana. Tradução: Roberto Raposo; Revisão técnica e apresentação: Adriano Correia - 13 ed. rev. - Rio de Janeiro: Forense Universitária, 2018.

ARENDT, Hannah. (1961). Entre o Passado e o Futuro. Tradução: Mauro W. Barbosa. São Paulo: Perspectiva, 2016.

ARENDT, Hannah. (1968). Homens em Tempos Sombrios. Tradução: Denise Bottmann; posfácio Celso Lafer - São Paulo: Companhia das Letras, 2008.

SCHÜTRUMPF, Jörn. (2008). Rosa Luxemburgo ou O preço da liberdade. Organizador: Jörn Schütrumpf. Traduções: Isabel Loureiro, Karin Glass, Kristina Michahelles e Monika Ottermann - 2 ed. rev. e ampl. - São Paulo: Expressão Popular, coedição Fundação Rosa Luxemburgo, 2015. 
NETTL, John Peter. (1974). Rosa Luxemburgo. Traducción: Félix Blanco. México: Ediciones Era.

LOUREIRO, Isabel. (2010). “Rosa Luxemburg e a Arte Da Política”. In. Marx Ahora Nr. 28, Havanna. Acessado em 05/07/2019 e encontrado em http://www.friggahaug.inkrit.de/documents/ Loureirorzfhluxembspan.pdf

MARTINS, Carla. (2005). “Arendt: uma perspectiva feminina do espaço público?”. Livro de Actas 4 SOPCOM. P. 701-711. Acessado em 06/07/2019 e encontrado em http://www.bocc.ubi.pt/ pag/martins-carla-rendt-perspectiva-feminina-espaco-publico.pdf

STORLØKKEN, Tanja. (2004). "Mulheres em tempos sombrios: Hannah Arendt e Rosa Luxemburgo". Tradução de Isabel Loureiro, revisão de Marcos Barbosa de Oliveira. Acessado em 05/07/2019 e encontrado em https://document.onl/documents/storlokken-tanja-mulheres-emtempos-sombrios-rosa-luxemburg-e-hannah-arendt.html

ARACY, Valerio. (2019). “O assassinato de Rosa Luxemburgo, cem anos depois”. Forum: 2019. Acessado em 10/09/2019 e encontrado em https://revistaforum.com.br/colunistas/o-assassinato-de-rosa-luxemburgo-cem-anos-depois/

Artigo recebido em: 20 de dezembro de 2019

Artigo aceito em: 09 de março de 2020 